\title{
A word's meaning affects the decision in lexical decision
}

\author{
JAMES I. CHUMBLEY and DAVID A. BALOTA \\ University of Massachusetts, Amherst, Massachusetts
}

\begin{abstract}
The influence of an isolated word's meaning on lexical decision reaction time (RT) was demonstrated through four experiments. Subjects in two experiments made lexical decision judgments, those in a third experiment pronounced the words used in the lexical decision task, and those in a fourth experiment quickly pronounced their first associative response to the words. Differences in lexical access time for the words were measured with the pronunciation task, and differences in meaning were assessed with the association task. Multiple regression analyses of lexical decision RT were conducted using associative RT, pronunciation RT, and other target word properties (printed frequency, length, instance dominance, and number of dictionary meanings) as predictor variables. These analyses revealed a relationship between lexical decision RT and associative RT after the effects of other variables had been partialed out. In addition, word frequency continued to have a significant relationship to lexical decision RT beyond that shared with pronunciation RT and the other variables. The results of these experiments indicate that at least some of the effect of word meaning and word frequency in lexical decision is attributable to a decision stage following lexical access.
\end{abstract}

Many theorists believe that at least two processes are involved in the attribution of meaning to a visually presented word. The word must be recognized by finding an entry in the mental lexicon that matches the stimulus, and the appropriate meaning of the lexical entry must then be determined. Three dominant theories of word recognition assert that the two processes, lexical access and meaning determination, are strictly sequential when reading an isolated word. They (Becker, 1980; Forster, 1978; Morton, 1979a, 1979b, 1982) assume that the process of accessing the lexical entry for a word involves matching the visual characteristics of the stimulus with an internal representation of the stimulus word. When the visual characteristics and the internal representation have sufficient overlap, the appropriate lexical entry has been located; lexical access has been accomplished. At this point, and only at this point, the meaning, pronunciation, and other information associated with the word become available. Within these theories, the meaning of an unprimed word plays no role in determining the ease with which lexical access is accomplished.

The principal task used to investigate the lexical access component of meaning attribution has been lexical deci-

This research was partially supported by a NIMH Postdoctoral Fellowship 5-25007 to the second author and a research grant from the Centronics Computer Corporation to the first author. Both authors contributed equally to this research project. We acknowledge the able assistance of Hayley Arnett throughout this research. The helpful comments of Charles C. Clifton, Jr., Jerome L. Myers, James H. Neely, and Keith Rayner on an earlier version of this paper are greatly appreciated. Requests for reprints may be sent to either James I. Chumbley, Department of Psychology, University of Massachusetts, Amherst, MA 01003, or to David A. Balota, Department of Psychology, Iowa State University, Ames, IA 50011. sion. In this task, the subject discriminates between words and nonword letter strings. Reaction time (RT) is the dependent variable of primary interest. Researchers have argued that subjects can make a lexical decision using only the minimal amount of information needed to determine the lexical status of the stimulus, that is, some match between the stimulus and an entry in the mental lexicon. It has been assumed that the role of semantic information is minimal, since it is not logically necessary to the tasks. In fact, as indicated above, the sequential nature of many current theories and their assumption that meaning plays no role in mapping a visual stimulus onto a unique lexical entry make it logically impossible for a word's meaning to influence speed of lexical access. Thus, it is somewhat surprising that studies using the lexical decision task (e.g., Balota \& Chumbley, 1984; James, 1975; Jastrzembski, 1981; Whaley, 1978) have found that the speed of responding to an isolated word is related to measures of the word's meaning. These findings are of major importance because they imply that: (1) semantic characteristics of the word being perceived in isolation are affecting the ease of lexical access, and/or (2) the lexical decision task involves components other than lexical access that are sensitive to the semantic characteristics of the word being judged. Both implications are important. Attributing the semantic effects to the lexical access component would force a major change in many current theories of word recognition. If the semantic effects are the result of some component of the lexical decision task other than lexical access, as Morton (1979b, 1982) believes, then additional caution must be exercised when using the task to study variables affecting lexical access. The series of studies reported here further examine the issue of the ex- 
istence of lexical decision task components that are not related to lexical access but are sensitive to semantic effects.

James (1975) was probably the first to demonstrate semantic effects on lexical decisions about words in isolation. He found that, in a lexical decision task with pronounceable nonwords, subjects made decisions about low-frequency concrete words more quickly than about low-frequency abstract words. Later, Whaley (1978) demonstrated that a cluster of semantic variables (concreteness, meaningfulness, imagery, and age of acquisition) significantly predicted lexical decision performance above and beyond obvious lexical variables such as printed word frequency and word length. More recently, Jastrzembski (1981) determined that the number of dictionary meanings of a word is an important predictor of lexical decision performance. We (Balota \& Chumbley, 1984) showed that instance dominance (I.DOM), a measure of the likelihood that a word will be given as an example of a category in response to the category name (Battig \& Montague, 1969), is related to RT in an unprimed lexical decision task. Each of these results suggests that semantic information may play a role in lexical access or at least in lexical decision performance.

In the present research, our aim is to investigate more directly the impact of semantic information on lexical decisions. The theoretical framework underlying the research assumes that the visual features of a word make available a number of different types of codes or representations that can be used for further processing (for similar arguments see, Allport, 1977, Balota, 1983, Gordon, 1983, and Marcel, 1983). For example, the subject may utilize visual characteristics, phonological characteristics, and semantic characteristics of the visual stimulus in retrieving an appropriate word. Although access to each of these representations is based initially on the visual stimulus, they may be used independently once they are activated. Word recognition involves the integration of these activated representations with any available context. Lexical decisions may be based on any combination of these types of information. Within this framework, lexical decision RT should be, at least in part, a function of the availability of a word's meaning and not be simply dependent upon the nonsemantic features of the word.

Given our view that meaning availability may affect lexical access and/or other components of the lexical decision task, we searched for a measure of meaning availability. The appropriate measure would be relevant to speeded lexical access but would not, in itself, involve strategic decision processes similar to those believed to be operating in the lexical decision task. There are many difficulties in obtaining such a measure. It is unclear whether semantic variables such as concreteness and imagery values faithfuly reflect meaning availability. It may be, for example, that the meaning of an abstract word such as "hate" is more readily available than the meaning of a concrete word such as "air" even though the words have similar frequencies in print. In addition, a word's fre- quency, the availability of its meaning, and the abstractness/concreteness of the word's referent are highly related. Finally, some unspecified nonsemantic variables that affect word recognition may be covarying with concreteness, imagery, and frequency. These sorts of difficulties have, in part, discouraged consideration of semantic variables in the available models of lexical access.

Since the traditional measures of meaningfulness are not unambiguously related to meaning availability, we took a different approach to the problem of finding a useful measure of meaning availability by utilizing a very "old" paradigm in a novel way. The task used was a simple associative RT task (Experiment 1) in which subjects were asked to pronounce the first associate that came to mind when presented with a given word. The associate and its latency were recorded. We felt that associative RT (with any effect of word frequency on it partialed out) should be an indicant of the amount of readily accessible meaning that a word has for a subject. If this variable predicts lexical decision performance (Experiments 2 and 3), then there would be evidence that availability of meaning is associated with ease of lexical access, at least in lexical access speed as it is measured by the lexical decision task.

The subjects' associates to the stimulus words yielded additional information that can be used to assess the impact of semantic variables on responding in the lexical decision task. If number of meanings is important in determining availability of meaning, then the number of different responses produced by our subjects to a word should predict lexical decision RT. The measure of the number of different associates (\#ARSP) has several advantages. First, it is based on the meaning search that, according to current theories of lexical access, follows lexical access. It should, therefore, not be related to lexical decision RT if lexical decision is a relatively pure measure of lexical access. Second, although it is not itself a response time, it is based on performance in a speeded task and may be more closely related to speeded tasks such as the lexical decision and pronunciation tasks than are measures such as I.DOM, number of dictionary meanings, etc.

A second purpose of the research was to further investigate the effects of I.DOM that we had found in an earlier study (Balota \& Chumbley, 1984). In that study, the words used came from 9 conceptual categories. With eight words from each of only 9 categories, it is possible that the observed reduction in RT with increasing I.DOM could somehow be attributed to implicit priming of lexical entries. The studies reported below ameliorate this problem by using only four words from each of 36 categories.

We expect that associative RT, \#ARSP, and I.DOM will predict lexical decision $\mathrm{RT}$, but these variables are related to a number of lexical variables (word frequency, word length, and number of syllables) that have known effects on lexical decision RT. For example, many investigators have demonstrated that lexical decision RT and pronunciation latencies decrease with increasing word frequency, and this word-frequency effect has dominated re- 
cent theoretical discussion of the word recognition process (see, Forster, 1981, Glanzer \& Ehrenreich, 1979, and Gordon, 1983). It is virtually impossible to orthogonally manipulate the above lexical variables along with I.DOM, associative RT, and \#ARSP. Thus, our data analyses used multiple regression techniques to analyze the relationship of lexical decision RT to associative RT, \#ARSP, I.DOM, number of dictionary meanings, and the lexical variables. In this way, we could determine if associative RT, \#ARSP, and I.DOM have unique effects on lexical decision RT beyond their shared influence with other theoretically motivated variables.

There is, of course, a problem with using a measure of meaning based on a speeded response to visually presented words. Specifically, in the theories of Becker (1980), Forster (1978), and Morton (1982), a unique lexical entry must be identified before a decision can be made that it is a word and before the meaning of the visual stimulus can be determined. Thus, the shared variance between lexical decision performance and associative response performance identified through regression analyses may be attributable simply to the assumption that both tasks require lexical access, the identification of a unique lexical entry. What is needed is some measure of lexical access time that does not itself depend upon semantic variables. This measure could then be used as an additional predictor variable to partial out the common lexical access component. One candidate for such a measure is pronunciation RT. In Experiment 4, we collected pronunciation RTs for the words used in Experiments 1, 2, and 3 and used pronunciation RT as an additional predictor variable for lexical decision RT.

The idea that pronunciation RT can be used as a predictor variable to partial out a lexical access component is based on the controversial assumption that pronunciation of a word normally involves lexical access. Some researchers have argued that pronunciation of visually presented stimuli may often not involve lexical access but may rely simply on phonological rules applied to the visual stimulus. Andrews (1982) reviewed this controversy. For the purposes of this paper, however, the fine points of the controversy are only tangentially relevant for four reasons. First, assume that lexical access is not generally involved in the pronunciation task. There still, however, must be a preliminary component, which Marcel and Patterson (1978) described as a transformation of the visual analysis of the written word to a graphic code. Thus, this transformation is a shared component, and it, at least, should be partialed out by using pronunciation RT as a predictor variable. Second, although there is some evidence for a process for pronouncing stimuli without recourse to lexical access, for example, a process based on graphic-phoneme corresondence rules (Coltheart, 1978), its properties seem to be such as to limit its utility for the mixture of regular and irregular word stimuli used in Experiment 4. There are both empirical (Coltheart, 1978) and logical grounds for believing that a process based on lexical access must be faster than a process with some other basis. Logically, if the nonlexical process were faster than the lexically based process, one would expect a large number of pronunciation errors in response to irregular words. If the lexical access process is appreciably faster, then it would seem reasonable to expect that the vast majority of pronunciations would be determined by a lexical access process and that pronunciation RT could be legitimately used as a predictor variable. Third, not all researchers believe that there are nonlexical processes for pronouncing words. Glushko (1981), for example, took strong exception to Coltheart's (1978) analysis of the process(es) by which pronunciations are determined. Finally, although the "correct" interpretation of the results of the analyses performed using pronunciation RT as one of the predictor variables will depend upon one's position with respect to the likelihood of pronunciation's involving lexical access, we believe the results presented below are interesting for the problems they pose for either interpretation.

\section{EXPERIMENT 1}

Associates and their latencies for a given word were obtained in this experiment for use as predictor variables in Experiments 2 and 3. Since the associative RTs are of interest in themselves, they were submitted to a multiple regression analysis using several predictor variables. First, since word frequency supposedly affects the ease of identifying a lexical entry (Becker, 1980; Forster, 1978; Morton, 1979b) and subjects must access the word's lexical representation to obtain the semantic information needed to produce an associate, associative RT should be a function of word frequency and word length. Second, \#ARSP, I.DOM, and number of dictionary meanings were used as predictor variables because they are measures of the meaningfulness of a word.

\section{Method}

Subjects. Twenty-four undergraduate students, recruited from the subject pool at the University of Massachusetts, Amherst, participated in partial fulfillment of course requirements.

Apparatus. The experiment was controlled by a North Star Horizon computer. Stimulus words were displayed in uppercase letters on a television monitor driven by an IMSAI memory-mapped video raster generator. In order to maximize legibility, all words were displayed with single spaces between letters. The subjects were seated approximately $50 \mathrm{~cm}$ from the video monitor. A three-letter word (three letters separated by two spaces) occupied a visual angle of approximately $1.1^{\circ}$, and a nine-letter word occupied a visual angle of approximately $3.7^{\circ}$. A voice key connected to the computer was triggered by the onset of a subject's voice. Response latency and interval timing were both measured with millisecond accuracy via the computer. The same apparatus was used for all the experiments reported in this paper.

Materials. The 144 target words selected for use in this study consisted of four exemplars from each of 36 different categories in the Battig and Montague (1969) norms. An attempt was made to select the words so that, for the four exemplars from a given category, there would be: (1) a high-frequency, high-dominant word; (2) a high-frequency, low-dominant word; (3) a lowfrequency, high-dominant word; and (4) a low-frequency , low- 
dominant word. On the basis of observations made by Whaley (1978), log frequency (LFREQ) was used instead of raw frequency (f) and was determined by the Kucera and Francis (1967) norms and the transformation LFREQ $=40+10 \log (f+1)$. The selection procedure resulted in word classes that had average LFREQ and I.DOM values of: (1) 57.953, 303.083, (2) 52.736, 38.306, (3) $51.970,286.722$, and (4) $47.635,40.139$, respectively. As can be seen, although our efforts to reduce some of the covariation in these variables were successful, we cannot claim to have orthogonally manipulated the two variables. Fifty words that were not members of the target categories were selected from the Kučera and Francis norms for use on practice and buffer trials. All words (targets and buffer/practice) ranged from three to nine letters in length. The complete list of target words, along with each word's mean RT and percentage error rate for each of the experiments, is presented in the Appendix.

Procedure. Each subject gave associates to practice words for two blocks of 15 trials. These practice blocks were followed by four test blocks of 41 test trials each. The buffer words were used for the first 5 trials of each test block. Target words were presented randomly within a test block, with the constraint that, within a test block, only one member of each of the 36 categories be presented. In this way, the four exemplars of a given category were presented in four different test blocks. This procedure eliminated any semantic priming within a block of trials by exemplars from the same conceptual category. The particular category exemplar presented in a test block was counterbalanced across subjects. In addition, to avoid any idiosyncratic groupings of the particular category exemplars, the combinations of category exemplars appearing together within a block were reordered such that each group of four subjects received different groupings of exemplars within their test blocks.

On each trial, the following sequence occurred: (1) a $500-\mathrm{Hz}$ warning tone was presented for $250 \mathrm{msec}$; (2) a 250 - $\mathrm{msec}$ interstimulus interval occurred; (3) the test word was presented until a vocal response was detected by the computer, at which point the word was erased from the screen; (4) the message "Response OK?" was presented; (5) the subject pulled one of two response levers to indicate that his/her voice, rather than some other sound (such as a cough), had triggered the computer. After the lever was pulled, there was a 4-sec intertrial interval before the tone signaling the next trial was presented.

All subjects were tested individually in a sound-deadened room. The microphone and two response levers (one indicating " $O K$ " and the other "not OK") were placed in front of the subjects. The subjects were instructed simply to say as quickly as possible the first word that came to mind when the stimulus word was presented. Any response, except the stimulus word itself, was acceptable. The experimenter monitored the subjects' responses via an intercom and recorded them. At the end of each block of trials, the subjects were given feedback regarding their average RT and the percentage of trials in which the "OK" lever had been pulled. There was a 10 sec mandatory rest between blocks, which was followed by a signal that the subjects could continue the experiment by a buttonpress when ready. A 2-sec delay was followed by the tone signaling the next trial.

\section{Results}

The relationship between associative RT and several variables will be examined. Variables for which large values correspond to strong, readily accessible meaning should correlate negatively with associative RT. I.DOM is an example of such a variable. Number of dictionary meanings and lexical decision RT are negatively correlated (Jastrzembski, 1981), and it is intuitively plausible that number of dictionary meanings would have a similar effect on associative RT. The log transformation given above was applied to the number of meanings listed in
Webster's New Collegiate Dictionary to produce the variable LMEAN. Word frequency (LFREQ) is known to be negatively correlated with lexical decision RT and should exhibit the same relationship to associative RT. We felt that associative RT would be shorter if a word had a single strong associate rather than several different responses (or only weak idiosyncratic responses). Thus, \#ARSP, the number of different associates given by the group of 24 subjects to a stimulus word, should correlate positively with associative RT. Finally, previous research and intuition suggest that RT should correlate positively with word length (LENG) and number of syllables in a word (SYLL).

Table 1 presents the correlation matrix, mean values, and standard deviation of these values for each of the predictor variables (I.DOM, LMEAN, \#ARSP, LFREQ, LENG, and SYLL) used in the experiments. Each measure is based on the values for all 144 words. Table 1 also presents the tolerance values for the predictor variables. The tolerances are a measure of the intercorrelations of the predictor variables and can vary between 0 and 1 . A tolerance value of 1 indicates that a given predictor variable is orthogonal to the other predictors. Ideally, of course, one would like tolerance values as close to 1 as possible. As can be seen in the first row giving tolerances, two variables (LENG and SYLL) have quite low values. An examination of the correlation matrix indicates that the primary reason for the low tolerances of these variables is that SYLL and LENG are highly correlated. Preliminary regression analyses indicated that SYLL never produced effects of even marginal significance, whereas its paired variable, LENG, had sizable predictive power. The decision was made, therefore, to eliminate SYLL from further consideration. The tolerance values for the reduced set of predictor variables are reasonably high.

The data used in all analyses of associative RT were the mean RTs for each word across subjects. In calculating the item means, the RTs for "outliers" and cases in

Table 1

Correlations, Means, and Standard Deviations for the Predictor Variables

\begin{tabular}{lrrrrrrr}
\hline \multicolumn{7}{c}{} & \multicolumn{5}{c}{ Predictor Variables } \\
\cline { 2 - 7 } & I.DOM & LFREQ & LENG & SYLL & LMEAN & \#ARSP \\
\hline I.DOM & 1.00 & & & & & \\
LFREQ & .402 & 1.00 & & & & \\
LENG & -.147 & -.206 & 1.00 & & & \\
SYLL & -.175 & -.313 & .740 & 1.000 & & \\
LMEAN & .298 & .436 & -.434 & -.532 & 1.000 & \\
\#ARSP & -.058 & .164 & .034 & -.081 & .185 & 1.000 \\
Mean & 167.104 & 52.601 & 5.653 & 1.799 & 47.220 & 11.181 \\
SD & 142.520 & 6.883 & 1.530 & .735 & 3.885 & 3.987 \\
Tolerances of: & & & & & & \\
$\quad$ Full Set & .799 & .704 & .438 & .388 & .603 & .911 \\
Subset & .799 & .713 & .797 & & .649 & .917 \\
\hline
\end{tabular}

Note - See text for definitions of variables. Tolerance $=1$ - the square of the multiple correlation of one predictor variable with the remaining predictor variables. 
which a subject responded "not OK" were replaced with the subject's grand mean of all "OK" responses.' To qualify as an outlier, the RT had to be less than $200 \mathrm{msec}$ or else more than three standard deviation units above the subject's mean RT for "OK" responses and also longer than $3 \mathrm{sec}$. The percentage of "not OK" responses was $1.85 \%$, and the percentage of outliers was $1.48 \%$.

A full multiple regresson analysis was conducted using the predictor variables I.DOM, LFREQ, LENG, LMEAN, and \#ARSP. The results of this analysis are shown in Table 2. The regression coefficients in Table 2, and in the following tables, have been partially standardized to ease interpretation. Each regression coefficient from the regression analyses has been multiplied by the standard deviation of the predictor variable with which it is associated. Partial correlation coefficients, F values, and correlations are unchanged by this procedure, and since the same words were used in all experiments, the standard deviations of the values of the predictor variables are constant across experiments. These semistandardized regression coefficients have the property of indicating the change in RT for each standard deviation unit change in the predictor variable. Thus, to obtain a reasonable estimate of an effect size for a predictor variable, one can simply multiply the regression coefficient by four to determine the size of the effect obtained across the range of the predictor variable used in the experiments. For example, for the words used in the present experiments, the unique effect of frequency on associative RT, as displayed in Table 2 , is $4 \times 48.77$, or approximately $200 \mathrm{msec}$. This effect is in addition to the shared effect that frequency has with the other predictor variables.

\section{Discussion}

Associative RTs were, on average, quite long. The average RT was on the order of $1.5 \mathrm{sec}$, about $1 \mathrm{sec}$ longer than most lexical decision and pronunciation RTs. They were also, as might be expected, highly variable. Not only were the times for different subjects for the same word quite variable, but the times across words were variable, a standard deviation of over $200 \mathrm{msec}$. As the regression analysis given in Table 2 shows, however, as- sociative RT is fairly easily characterized. Short, highfrequency words that have only a few dominant meanings are responded to quickly.

In Experiment 1, we attempted to obtain a measure of meaning availability to use in investigating meaning effects in lexical decision. The question now is, will associative $\mathrm{RT}$ be related to lexical decision response latency when the shared effects with LFREQ, LENG, and \#ARSP have been partialed out?

\section{EXPERIMENT 2}

The primary purpose of Experiment 2 was to gather data to explore the relationship between lexical decision RT, associative RT, \#ARSP, and the lexical and meaning predictor variables used above.

\section{Method}

Subjects. Twenty-four undergraduate students were recruited from the same pool described in Experiment 1. No subject participated in both Experiments 1 and 2 .

Materials. Targets in the lexical decision task were the words used in Experiment 1 (see Appendix). There were 194 pronounceable nonword foils. The nonwords used by Balota (1983) were supplemented with nonwords based on words selected from the Kučera and Francis (1967) norms. The pronounceable nonwords were produced by changing up to three letters within the word (e.g., "season" was changed to "seshon').

Procedure. The procedure in Experiment 2 was very similar to that in Experiment 1, except that: (1) on each trial, a word or nonword was presented and the subjects' task was to pull one lever to indicate "word" or a second lever to indicate "nonword"; (2) there were two practice blocks of 30 trials and eight test blocks of 41 trials, the first five items in each test block being buffer items; and (3) whenever the subjects pulled the incorrect lever, they were given an error message and required to press a button to continue the experiment when they were ready. Items were again counterbalanced across blocks, such that one member of each of the 36 catergories was presented once every two blocks. The subjects were encouraged to be as fast and as accurate as possible. Twelve subjects used the dominant hand to respond "word," and 12 subjects used the nondominant hand to respond "word."

\section{Results}

The data for Experiment 2 were analyzed in the same fashion as those for Experiment 1. For each word, an

Table 2

Regression Analysis for Experiment 1, With Associative Reaction Time (RT) as Criterion Variable (Mean RT $=1451.618$, SD RT $=205.265$ )

\begin{tabular}{|c|c|c|c|c|c|}
\hline & \multicolumn{5}{|c|}{ Predictor Variable } \\
\hline & I.DOM & LFREQ & LENG & LMEAN & \#ARSP \\
\hline Regression Coefficient & -20.304 & -48.770 & 52.174 & -11.201 & 119.523 \\
\hline$F(1,138)$ & 2.204 & 11.348 & 14.515 & $<1$ & 87.628 \\
\hline $\mathrm{p}$ & .140 & $<.001$ & $<.001$ & & $<.001$ \\
\hline $\mathrm{r}$ & -.282 & -.258 & .361 & -.190 & .548 \\
\hline \multirow[t]{2}{*}{ Partial $\mathbf{r}^{2}$} & .016 & .076 & .095 & .004 & .388 \\
\hline & $\mathrm{R}^{2}=.510$ & \multicolumn{2}{|c|}{$F(5,138)=28.781$} & & \\
\hline
\end{tabular}

Note-The regression coefficients have been "semistandardized" by multiplying by the standard deviation of the predictor variable (see text). The standard error of a regression coefficient is equal to the coefficient divided by the square root of its $F$. 
average RT across subjects was calculated excluding errors and outliers. Outliers were determined by the same criterion as in Experiment 1, except that a long cutoff of $850 \mathrm{msec}$ was used instead of $3 \mathrm{sec}$. The error rate for words was $6.74 \%$, and the percentage of outliers was $1.71 \%$. For nonwords, the average RT for correct responses was $637.86 \mathrm{msec}$, and the error rate was $3.79 \%$. The scored data were then submitted to two different full multiple regression analyses, shown in the two halves of Table 3 .

In the upper portion of Table 3 , the regression analysis included the predictors used in Experiment 1. The only predictor variable that had a significant independent effect on lexical decision RT was LFREQ. None of the other variables had any independent predictive power. ${ }^{1}$

The lower portion of Table 3 exhibits the results when associative RT is included as a predictor variable. The significant predictors of lexical decision RT in this analysis are \#ARSP, associative RT, and, again, LFREQ. None of the other variables had any unique predictive power.

Although associative RT is a remarkably good predictor of lexical decision RT, it does not appear to be a pure measure of availability of meaning. This can be seen by noting that \#ARSP is acting as a suppressor variable for associative RT; that is, \#ARSP corrects for or suppresses error in using associative RT as a predictor for lexical decision RT. The effect of the suppression is that the partial $\mathrm{r}^{2}$ for \#ARSP is actually larger than the raw correlation. A more exact explanation of this effect is given below.

\section{Discussion}

The most important result of Experiment 2 is that lexical decision RT is very highly related to associative RT. Before considering this effect of associative RT more closely, however, there are four other points that should be noted.

First, a strong word-frequency effect was obtained. This frequency effect is in addition to the frequency effect that predicts associative RT. This is surprising, since one might expect that the frequency effect that is predictive of associative RT at least includes the frequency effect that is widely thought to be involved in lexical access. This would seem to imply that word frequency is affecting some component other than lexical access in lexical decisions.

Second, I.DOM had no effect on lexical decision performance. Balota and Chumbley (1984) found a significant but small effect of I.DOM in their lexical decision task. Perhaps the use of a larger number of categories and fewer words per category in the present experiment reduced the effect of I.DOM.

Third, there was a complete absence of the LMEAN effect found by Jastrzembski (1981). We have not looked for this effect in previous experiments, but the failure to replicate was puzzling.

Finally, there was no influence of LENG on lexical decision performance. This is also surprising, since a number of researchers have found length effects in lexical decision performance (e.g., Balota \& Chumbley, 1984; Forster \& Chambers, 1973). The absence of a length effect in Experiment 2 raised serious questions in our minds about the representativeness of the results of Experiment 2 , and we felt that it was necessary to conduct a third experiment to determine why the I.DOM, LMEAN, and LENG effects were not found.

\section{EXPERIMENT 3}

In reviewing the nonwords used in Experiment 2, we noticed that the 194 nonwords averaged approximately

Table 3

Regression Analyses for Experiment 2, With Lexical Decision Time for Words as Criterion Variable $($ Mean RT $=565.940$, SD RT $=61.165$ )

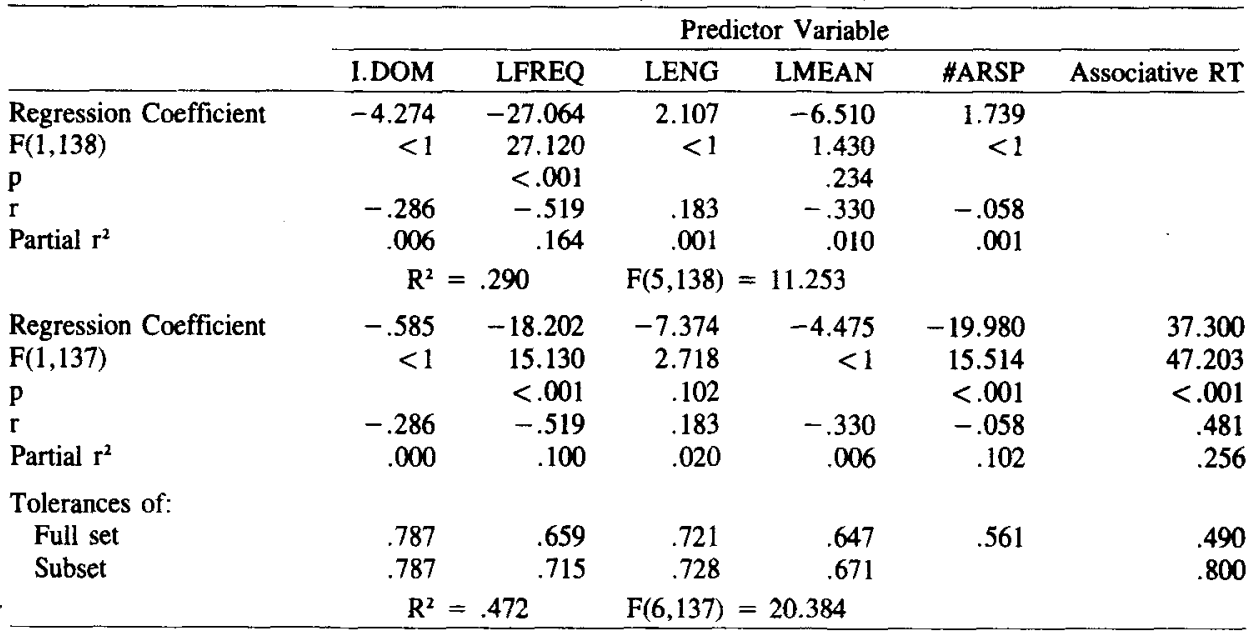

Note-The upper portion of the table presents the results for the same predictor variables as in Experiment 1 . The lower portion presents the results when associative $R T$ is added as a predictor variable. 
one letter less than the 194 buffer/practice and target words (word mean $=5.54$, range of 3 to 9 ; word mean $=$ 4.55 , nonword range of 3 to 8 ). Although this was only a small difference (none of the subjects spontaneously reported noticing such a difference), it may have influenced the subjects' response strategies such that they could have responded "word" whenever a very long stimulus was presented. Thus, length may have had two opposing effects in Experiment 2: Long words may have required more time for lexical access; but long stimuli, on some trials, may have been responded to quickly without lexical access. These two opposing length effects could have negated each other, thereby eliminating any overall length effect.

The availability of the length cue may also have affected the presence of I.DOM and LMEAN effects, since using length as a cue would have reduced the need for lexical access and/or the need to check for stimulus meaningfulness (cf. Balota \& Chumbley, 1984). In addition, it may be that meaning variables are more important with long words, since long words may vary more than short words on the meaning dimension. For example, long words tend to have fewer dictionary meanings (cf. the -.434 correlation between LMEAN and LENG in Table 1). If subjects tended on some trials to respond "word" to very long stimuli without determining whether the stimuli actually were words, the role of meaning in the judgments would have been diminished. To explore this possibility, we equated more exactly both the average length and the range of the lengths across the words and nonwords in Experiment 3. We expected to find in this experiment the more typical length effect, that is, that longer words would produce longer response latencies. In addition, if the subjects were using length cues to bypass the need for lexical access on some trials and if meaning evaluation is a component of lexical decision, then eliminating the length cues should produce a reappearance of meaning (I.DOM and LMEAN) effects.

\section{Method}

Subjects. Twenty-four undergraduate students were recruited from the same pool described in Experiment 1. No subject had participated in either of the two previous experiments.

Materials. The words employed in this experiment were those from Experiments 1 and 2. The only difference between Experiments 2 and 3 was in the nonwords. Additional words were selected from the Kučera and Francis (1967) norms and were used to produce long pronounceable nonwords. Some short nonwords from Experiment 2 were replaced by these new nonwords. For the new set of nonwords, the mean length (5.52) and range (3 to 9) of the 194 nonwords now matched the length (5.54) and range ( 3 to 9 ) of the 194 buffer/practice and target words.

Procedure. The procedure was identical to that of Experiment 2.

\section{Results}

Analysis of the data for Experiment 3 was identical to that for Experiment 2. The error rate for words was $6.97 \%$ and the outlier rate was $1.68 \%$. For nonwords, the mean RT for correct responses was $672.45 \mathrm{msec}$, and the error rate was $4.75 \%$.

The results displayed in the upper portion of Table 4 are very different from those found in Table 3 . While the LFREQ effect is still very robust, there are now significant effects of I.DOM, LENG, and LMEAN. \#ARSP still has no effect on lexical decision task RT when entered into a regression analysis without associative RT.

The lower portion of Table 4 shows the same effects found in Experiment 2: LFREQ has an additional effect over and beyond that shared with associative RT; associative RT is a good predictor of lexical decision task RT; and \#ARSP is negatively related (as a suppressor variable) to RT in the lexical decision task. Note, however, that the predictive powers of I.DOM and LENG are reduced to nonsignificant levels by the introduction of associative RT into the analysis. LMEAN, however, continues to be a significant predictor of response speed in the lexical decision task.

\section{Discussion}

The results of Experiment 3 were quite different from

Table 4

Regression Analyses for Experiment 3, With Lexical Decision Time for Words as Criterion Variable (Mean RT $=$ 579.395, SD RT $=$ 59.821)

\begin{tabular}{lrrrrrr}
\hline & \multicolumn{5}{c}{ Predictor Variable } \\
\cline { 2 - 7 } & I.DOM & LFREQ & LENG & LMEAN & \#ARSP & Associative RT \\
\hline Regression Coefficient & -9.251 & -22.680 & 14.015 & -9.833 & 1.318 & \\
F(1,138) & 4.743 & 25.444 & 10.859 & 4.357 & $<1$ & \\
$\mathrm{p}$ & .031 & $<.001$ & .001 & .039 & & \\
$\mathrm{r}$ & -.392 & -.558 & .407 & -.473 & -.053 & \\
Partial $\mathrm{r}^{2}$ & .033 & .156 & .073 & .031 & .001 & \\
& $\mathrm{R}^{2}=.444$ & $\mathrm{~F}(5,138)$ & 22.049 & & \\
Regression Coefficient & -6.039 & -14.963 & 5.760 & -8.061 & -17.593 & 32.473 \\
$\mathrm{~F}(1,137)$ & 2.667 & 13.271 & 2.225 & 3.911 & 16.143 & 48.028 \\
$\mathrm{p}$ & .105 & $<.001$ & .138 & .050 & $<.001$ & $<.001$ \\
$\mathrm{r}$ & -.392 & -.558 & .407 & -.473 & -.053 & .535 \\
Partial $\mathrm{r}^{2}$ & .019 & .091 & .016 & .028 & .105 & .260 \\
& $\mathrm{R}^{2}=.588$ & $\mathrm{~F}(6,137)=32.640$ & & \\
\hline
\end{tabular}

Note-The upper portion of the table presents the results for the same predictor variables as in Experiment 1. The lower portion presents the results when associative RT is added as a predictor variable. 
those of Experiment 2, even though the only difference between the two experiments was a small difference in length of the nonwords. Again, in Experiment 3, there were large effects of LFREQ and associative RT. However, there also were large effects of LENG and I.DOM (when associative RT is not used as a predictor) and an effect of LMEAN. Together, the absence in Experiment 2, and then the presence in Experiment 3 of LENG, I.DOM, and LMEAN effects gives some credence to the hypothesis that the use of length as a cue by subjects in Experiment 2 eliminated the weakest meaning effects (I.DOM and LMEAN). When, in Experiment 3, length could no longer be used as a cue for responding "word" to some stimuli, the meaning of the stimulus became a more important factor. The covariation of the LENG and meaning effects gives some support for the conjecture that long words may vary more along meaning dimensions than do short words, which makes meaning a very salient dimension for these words in determining lexical decision RT

The argument that the length difference between words and nonwords in Experiment 2 might bias subjects to respond "Yes" to long words without actually resorting to lexical access implies that word RTs should be longer in Experiment 3 than in Experiment 2. In fact, mean word RT for Experiment 2 is slightly $(13 \mathrm{msec})$ faster than it is in Experiment 3. This difference is not significant $(t<1)$ when each subject's mean RT for words is the basic datum, but when RT is averaged across subjects for each word and a direct difference $t$ test comparing $R T$ in each experiment for each word is conducted, the difference is highly significant $[t(143)=4.715, p<.001]$. That the effect is quite small is not surprising, since only long words could be responded to without lexical access.

The existence of LENG and meaning (I.DOM and LMEAN) effects in Experiment 3 and their absence in Experiment 2 fits quite nicely with a two-stage model of the lexical decision task presented by Balota and Chumbley (1984). A description of this model and a discussion of the different patterns of effects in Experiments 2 and 3 are provided in the General Discussion section. First, however, the problem of another basis for a relationship between associative responding and lexical decision performance must be considered.

As indicated earlier, one process that should be involved in both the associative response and lexical decision tasks is lexical access. A possible reason that associative RT is so strongly related to lexical decision RT is simply that the subject must first access the lexicon to produce an associate and must also access the lexicon to make a lexical decision. This "lexical access" component of both tasks may be why the associative task RTs and lexical decision performance are strongly related. Thus, the results presented so far may have little to do with subjects' using meaning in lexical access or in a decision stage of lexical decision. Instead, they may mean that word recognition is being affected by some other very powerful unidentified variable, a variable that is independent of the effects of known variables such as word frequency, word length, and meaning. This, in itself, would be an important finding. The effect of \#ARSP on lexical decision RT, however, fits better with a meaning explanation of the associative RT effect. In any case, we attempted to provide at least a partial solution to the problem of shared visual analysis and lexical access components in lexical decision and associative responding by collecting pronunciation RTs for the words used in Experiments 1, 2, and 3. Pronunciation RT will then be used as an additional predictor variable in reanalyses of Experiments 2 and 3.

\section{EXPERIMENT 4}

In this experiment, we simply obtained pronunciation RTs for the 144 target words. These pronunciation RTs will be used to predict the lexical decision results of Experiments 2 and 3 . Our major interest will be in determining whether associative RT still predicts lexical decision performance after the lexical access component common to all three tasks has been partialed out using pronunciation RT. If it does, then this would suggest that the lexical decision task has a meaning component and that this component is not in the lexical access stage.

\section{Method}

Subjects. Twenty-four undergraduate students were again recruited from the same pool as those in the earlier experiments. No subject had participated in any of the earlier experiments.

Materials. The materials were exactly the same as those used in Experiment 1.

Procedure. The procedure was exactly the same as that for Experiment 1 , except that the subjects were asked to pronounce each word quickly rather than say an associate to the word.

\section{Results}

The data from Experiment 4 were scored in exactly the same fashion as those for Experiment 1, except that the long cutoff was $850 \mathrm{msec}$. The percentage of "Not OK" responses (i.e., a word was mispronounced, etc.) was $1.48 \%$ and the percentage of outliers was $2.11 \%$. A regression analysis of the pronunciation RT data was conducted to determine the effect of lexical and meaning variables on pronunciation RT. The results of this analysis are presented in Table 5.

The regression analysis indicates that, as Balota and Chumbley (1984) found, only LFREQ and LENG predict pronunciation RT. Both effects are very robust; in fact, they are slightly larger than those found in Experiment 3. I.DOM, LMEAN, and \#ARSP did not have significant effects on pronunciation $\mathrm{RT}$.

\section{Discussion}

The results of the analysis of the pronunciation task RTs indicate that it is suitable for use as a predictor variable that measures the lexical access component of tasks in which words are being used as stimuli. The effects of LFREQ and LENG are large, and these are two variables that have played major roles in theoretical accounts of lexical access. I.DOM and LMEAN play a small role in 
Table 5

Regression Analysis of Experiment 4, With Pronunciation Latency as Criterion Variable $($ Mean RT $=551.926$, SD RT $=71.600)$

\begin{tabular}{lrrrrr}
\hline & \multicolumn{5}{c}{ Predictor Variable } \\
\cline { 2 - 6 } & I.DOM & LFREQ & \multicolumn{1}{c}{ LENG } & LMEAN & \#ARSP \\
\hline Regression Coefficient & -1.831 & -27.061 & 26.015 & -9.880 & 2.934 \\
$\mathrm{~F}(1,138)$ & $<1$ & 25.483 & 26.322 & 3.095 & $<1$ \\
$\mathrm{P}$ & & $<.001$ & $<.001$ & .081 & \\
$\mathrm{r}$ & -.275 & -.517 & .506 & -.461 & -.032 \\
Partial r $^{2}$ & .001 & .156 & .160 & .022 & .003 \\
& $\mathrm{R}^{2}=.448$ & $\mathrm{~F}(5,138)=22.437$ & & \\
\hline
\end{tabular}

pronunciation, and their role as predictors for lexical decision should be unaffected by the inclusion of pronunciation RT as a predictor variable.

\section{REANALYSES OF EXPERIMENTS 2 AND 3}

There are two strong competing predictions about what should happen when pronunciation RT is added to the set of predictor variables in the lower portions of Tables 3 and 4. First, lexical decision RT, associative RT, and pronunciation RT are related through the shared lexical access component. If this is the only relationship, then the variance being explained by associative RT in Tables 3 and 4 should become part of the variance shared by pronunciation RT and associative RT when pronunciation $\mathrm{RT}$ is entered into the regression analysis. Thus, associative RT should have a nonsignificant effect when pronunciation RT is entered, because the shared lexical access effect has been partialed out. Similarly, if LFREQ's main role in determining lexical decision RT is the result of its role in lexical access, it should no longer have a unique effect.

On the other hand, assume lexical decision RT and associative RT are related through an effect of meaning on some component of lexical decision other than lexical access. Under this assumption, associative RT should have a significant effect beyond its shared effect with pronunciation RT. In the same manner, if LFREQ is affecting lexical decision times through some component other than lexical access, then there should still be a significant LFREQ effect after the lexical access effect has been partialed out. Table 6 displays the results of the appropriate analyses.

As can be seen in both the upper and lower portions of Table 6, associative RT maintains a clearly significant relationship with lexical decision times in both Experiments 2 and 3 , even after the lexical access component has been partialed out by including pronunciation RT as a predictor variable. LFREQ has less striking effects, but they are nonetheless marginally significant. Thus, the results obtained by including pronunciation $\mathrm{RT}$ as a predictor contradict the hypothesis that associative RT is related to lexical decision RT solely because the two tasks share a common lexical access component. Instead, it seems that meaning and word frequency are affecting other stages of lexical decision and/or that meaning is having some role in determining ease of lexical access in a manner unique to the lexical decision task.

Table 6

Additional Regression Analyses on the Lexical Decision Times of Experiments 2 and 3

\begin{tabular}{|c|c|c|c|c|c|c|c|}
\hline & \multicolumn{7}{|c|}{ Predictor Variable } \\
\hline & I.DOM & LFREQ & LENG & LMEAN & \#ARSP & Associative RT & Pronunciation RT \\
\hline \multicolumn{8}{|c|}{ Criterion Variable $=$ Experiment 2 Lexical Decision Time } \\
\hline $\begin{array}{l}\text { Regression Coefficient } \\
\mathrm{F}(1,136) \\
\mathrm{p} \\
\mathrm{r} \\
\text { Partial } \mathrm{r}^{2}\end{array}$ & $\begin{array}{r}-1.730 \\
<1 \\
-.286 \\
.002\end{array}$ & $\begin{array}{r}-8.761 \\
4.517 \\
.035 \\
-.519 \\
.032\end{array}$ & $\begin{array}{r}-15.895 \\
16.430 \\
<.001 \\
.183 \\
.108\end{array}$ & $\begin{array}{r}-.336 \\
<1 \\
-.330 \\
.000\end{array}$ & $\begin{array}{r}-9.017 \\
4.018 \\
.047 \\
-.058 \\
.029\end{array}$ & $\begin{array}{r}15.764 \\
8.626 \\
.004 \\
.481 \\
.060\end{array}$ & $\begin{array}{r}38.521 \\
58.043 \\
<.001 \\
.731 \\
.299\end{array}$ \\
\hline $\begin{array}{l}\text { Tolerance of: } \\
\text { Full Set } \\
\text { Subset }\end{array}$ & $\begin{array}{l}.787 \\
.786\end{array}$ & $\begin{array}{l}.599 \\
.614\end{array}$ & $\begin{array}{l}.662 \\
.663\end{array}$ & $\begin{array}{l}.635 \\
.647\end{array}$ & .503 & $\begin{array}{l}.354 \\
.644\end{array}$ & $\begin{array}{l}.398 \\
.444\end{array}$ \\
\hline \multicolumn{8}{|c|}{$R^{2}=.630$} \\
\hline \multicolumn{8}{|c|}{ Criterion Variable $=$ Experiment 3 Lexical Decision Time } \\
\hline $\begin{array}{l}\text { Regression Coefficient } \\
F(1,136) \\
p \\
r \\
\text { Partial } r^{2}\end{array}$ & $\begin{array}{r}-7.003 \\
4.966 \\
.027 \\
-.392 \\
.035\end{array}$ & $\begin{array}{r}-7.017 \\
3.808 \\
.053 \\
-.558 \\
.027 \\
\mathbf{R}^{2}=.\end{array}$ & $\begin{array}{r}-1.412 \\
<1 \\
\\
.407 \\
.001 \\
705\end{array}$ & $\begin{array}{r}-4.576 \\
1.716 \\
.192 \\
-.473 \\
.012 \\
F(7,136)=\end{array}$ & $\begin{array}{r}-8.366 \\
4.546 \\
.035 \\
-.053 \\
.032 \\
46.531\end{array}$ & $\begin{array}{r}14.348 \\
9.397 \\
.003 \\
.535 \\
.065\end{array}$ & $\begin{array}{r}32.420 \\
54.047 \\
<.001 \\
.796 \\
.284\end{array}$ \\
\hline
\end{tabular}


The results of the new analyses are more mixed with respect to the other meaning variables. I.DOM is still marginally significant in Experiment 3, but LMEAN is no longer significant. It is not clear why this should be the pattern of results, except that the effect of LMEAN was approaching significance in the pronunciation task (Table 5) and the analyses in Table 6 incorporate this effect. This would result in partialing out the LMEAN effect of Experiment 3.

An intriguing and unexpected finding in the reanalyses is that pronunciation RT has a relationship to lexical decision RT over and above the effects of a fairly complete set of previously identified theoretically relevant predictor variables. The analyses displayed in Table 6 are clear evidence that there are yet some other unidentified major factors operating in these tasks. It is not clear, however, that the unidentified variables are affecting lexical access, since they do not affect associative RT. Lexical access was assumed to be a component common to all three tasks. If these unidentified factors had been affecting lexical access, then they would have been partialed out and pronunciation RT would not have had a unique effect in predicting lexical decision RT.

Finally, the surprising effect of \#ARSP is still present in both experiments, and it has been joined by another surprising effect, a significant LENG effect in Experiment 2. Although it is not surprising that LENG should affect lexical decision RT, it is not immediately clear why the lexical entries for long words should be found more quickly than those for short words. Both of these effects can be readily understood by noting that both \#ARSP and LENG are classic suppressor variables (Darlington, 1968).

First, consider the negative correlation between \#ARSP and lexical decision time: The greater the number of different associative responses given by the group of 24 subjects, the faster the lexical decision RT. In introducing this variable, it was noted that associative RT should be short if there is one strong and readily accessible associate of the presented word. If \#ARSP is taken as a measure of the degree to which there are several competing available responses, then one would expect associative $\mathrm{RT}$ to increase as a function of response competition. The regression results in Table 2 indicate that this was the case-associative RT and \#ARSP are positively related. Now, for the present purposes, assume that meaning strength is somehow related to lexical decision time and that both the number of meanings and their strengths determine total meaning strength. Support for this assumption can be found in the negative relationship between LMEAN and lexical decision time; that is, the more dictionary meanings, the faster a lexical decision is made. But associative RT is not a "pure" measure of strength of meaning; it is contaminated by the response competition measured by \#ARSP. Some of the long associative RTs were for words with many, but weak, available meanings. Under these conditions, \#ARSP fits the classic defi- nition of a supressor variable (cf. Darlington, 1968, pp. 163-165). It has essentially no validity with respect to lexical decision RT ( $r$ is nearly zero), it is positively correlated with associative RT, and lexical decision RT and associative RT are positively correlated. Darlington indicated (p. 164) that under these conditions variables such as \#ARSP "suppress," subtract out, or correct for a source of error in the measured relationship between associative RT and lexical decision RT. The negative regression coefficient for \#ARSP is the result of this suppression effect. It should be noted that the role of \#ARSP as a suppressor variable does not mean it is related to lexical decision. It is just that it permits the true relatedness of another variable, in this case associative $\mathrm{RT}$, to be seen more clearly. If \#ARSP is not included as a predictor variable for lexical decision RT, the measures of observed relatedness of associative RT to lexical decision RT, that is, the regression coefficient and partial $\mathbf{r}^{2}$, decrease by about $50 \%$ (although they are still significant).

Given the assumption that \#ARSP is a measure of response competition, one would also expect to find it operating as a suppressor variable for pronunciation latency; pronunciation RT of a word may be long if presentation of the word evokes many responses instead of only the word itself and one strong associate. This is in fact the case. If associative RT is incorporated as an additional predictor variable for the pronunciation RT data in Table 5, a significant suppression effect is found for \#ARSP. In addition, the relationship between \#ARSP and pronunciation RT strongly suggests that lexical access was involved in pronouncing the words in Experiment 4.

Consideration of the role of LENG as a suppressor variable explains the significant negative regression coefficient for LENG in the reanalysis of Experiment 2 lexical decision RT shown in Table 6. Assume pronunciation RT is a relatively pure measure of the degree to which the lexical entries for short words are more easily located than those for long words. Then, to the extent that the subjects were using the strategy of responding "word" to very long stimuli, pronunciation RT will be less related to lexical decision RT. Long words will be pronounced slowly, but lexical decision RT will be relatively short. LENG "suppresses" this error, since it has only a small positive correlation with lexical decision RT in Experiment 2 , it is positively correlated with pronunciation $\mathrm{RT}$, and lexical decision RT is positively correlated with pronunciation $\mathrm{RT}$. The result is the negative regression coefficient for LENG in Experiment 2. In Experiment 3, word and nonword length were carefully equated, and the bias to respond "Yes" to long stimuli was not possible, so no "correction" was required. Lexical decision and pronunciation shared the same LENG effect under these conditions so the regression coefficient is essentially zero in Table 6 (but not Table 4 where the LENG effect has not been partialed out by the inclusion of pronunciation $\mathrm{RT}$ as a predictor variable). 


\section{GENERAL DISCUSSION}

The complicated set of results presented above can be quite easily summarized. First, when physical properties of the stimuli, for example, word length, make it possible to use response strategies unrelated to lexical access, the effects of these strategies will be seen in the data. In addition, it is not clear that these were conscious strategies on the part of subjects. In their efforts to make fast and accurate decisions about the appropriate response to a stimulus, they used all sorts of information, not just information about the "wordness" of the stimulus. Second, when the most obvious of such strategies was impossible, the subjects somehow used the meaning of the stimulus (as measured by I.DOM, LMEAN, and associative RT) to make lexical decisions. Third, the effect of LFREQ is not localized in the lexical access component of lexical decision. It has an effect on lexical decision RT beyond its shared effect on the lexical access common to the three tasks. Finally, there is evidence that at least one other major, but presently unidentified, variable affects lexical decision and pronunciation but not associative responding. Since the effect of the variable is not shared by all three tasks, it is questionable whether it affects lexical access.

\section{Implications for Theories of Word Recognition}

The implications of these results for theories of word recognition that assume that lexical access precedes meaning attribution (Becker, 1980; Forster, 1978) are quite clear. Evidence from the lexical decision task for these theories is, at best, equivocal. Two important assumptions of the theories, that the word-frequency effect in lexical decision is localized in lexical access and that semantic variables do not affect lexical decisions about isolated words because a word's meaning is available only after lexical access, are clearly wrong. It may be that lexical access involves a search of the lexicon, but the existence of a word-frequency effect on the lexical decision task does not imply that word frequency orders this search. It appears, instead, as Morton (1979b, 1982) hypothesized, that processes occurring after lexical access (in, e.g., Morton's "cognitive system") are involved in making a lexical decision.

Two theories of the lexical decision task make such decision processes explicit. Balota and Chumbley (1984) and Gordon (1983) have proposed models of the lexical decision task that assume subjects use a variety of types of information in making lexical decisions. In our model, we refer to one type of composite information as familiarity/meaningfulness (FM). The basic idea is that when a word or nonword stimulus is presented, it evokes an FM value because of its orthographic and phonological similarity to the internal representations of one or more words. The subject attempts to use this FM value in making a rapid decision. The degree of similarity to the stored representation(s) determines the strength of the FM response. If the FM value is very large, the subject as- sumes that it is very likely the result of a word's being presented and responds "word." If the value is very low, the stimulus is likely to be a nonword, so a "nonword" response is made. If the stimulus had produced an intermediate FM value, one that could be the result of the presentation of a very "wordlike" nonword or a very unfamiliar word, then the subject must perform a slow analytic check of the stimulus to avoid making an error.

We have shown (Balota \& Chumbley, 1984) that our model is in accord with a large body of lexical decision results and provides explanations for data that have proven troublesome to a number of current models of word recognition. We have used the model to provide explanations for three kinds of data: the effect of frequency-blocking on lexical decision (Glanzer \& Ehrenreich, 1979; Gordon, 1983) but not pronunciation (Forster, 1981); the effect of repeating words and nonwords on lexical decision (Duchek \& Neely, 1984; McKoon \& Ratcliff, 1979; Scarborough, Cortese, \& Scarborough, 1977; Scarborough, Gerard, \& Cortese, 1979); and the effect on lexical decision of using unpronounceable rather than pronounceable nonwords (James, 1975; Scarborough et al., 1977; Schuberth \& Eimas, 1977). It should also be clear that this same type of analysis is compatible with the results of Experiment 2. If a stimulus was very long, it was almost certainly a word, and, on some trials, there was no need for the subject to evaluate the string's FM value. The availability of this strategy effectively eliminated I.DOM and LMEAN effects in Experiment 2, but in Experiment 3 , in which there was no basis for a length-based strategy, I.DOM and LMEAN predicted RT.

The difference between our model and those of Becker (1980) and Forster (1978) in interpreting the results of lexical decision experiments is important. We assume that when the FM value is very large or very small, a lexical decision response can be initiated on the basis of the composite information even before the subject has determined that the stimulus is a word by finding a match of the visual and/or phonological features of the stimulus with the internal representation of one of the word candidates. In contrast, Becker and Forster propose that the decision to respond "word" is the result of finding a satisfactory match of the stimulus features with an internal representation of a particular word. Finding this match is necessary and sufficient for making the response "word." Thus, if lexical access is defined as accomplishment of a satisfactory match to a single word, we do not assume that lexical access necessarily precedes the word/nonword decision, whereas Becker and Forster do. That is, Becker and Forster assume that for isolated words, there is a strictly sequential process of lexical access and then meaning extraction. We do not share this assumption.

Gordon's (1983) model also assumes that subjects use a variety of types of information in making judgments about stimuli in lexical decision. In contrast to our model, however, Gordon assumes that rate of information extraction differs for stimuli: Following a given time interval, the information available for high-frequency words is 
greater than that for low-frequency words and nonwords. When the amount of information available exceeds a threshold amount, then a "word" response is immediately made. If the threshold has not been exceeded by a deadline, then a "nonword" response is made. This model explains the frequency effect for words but, unfortunately, cannot explain other important findings for nonwords. For example, both Scarborough et al. (1977) and Shuberth and Eimas (1977) have found that correct responses to pronounceable nonwords are slower than correct responses to nonpronounceable nonwords in a mixed list task. Gordon's model predicts that nonword RTs should not differ in this way, since the "nonword" response is a default response for stimuli whose information value has not exceeded the threshold by the deadline. Of course, Gordon was most interested in dealing with the frequencyblocking effect on word RT, and it is possible he could make minor revisions in his model to deal more adequately with the nonword results of other types of experiments.

Morton's $(1970,1979 a, 1979 b, 1982)$ logogen theory is compatible with the present results. In Morton's theory (as applied to visually presented stimuli), the visual input logogens determine the lexical entry (if any) to which the stimulus corresponds. This logogen then activates the appropriate parts of the cognitive system, which makes available the meaning of the stimulus, and the output logogen, which enters the word into the response buffer. A lexical decision could be made on the basis of either of these two events, the availability of meaning or the availability of a word. Morton (1970, p. 214) even proposed that the degree of logogen activation required to trigger the cognitive system may be less than that required to trigger an entry into the response buffer. Thus, the logogen model is very compatible with the experimental results presented above and, in fact, provides a good mechanism for producing the FM values and analytic checks postulated in the Balota and Chumbley (1984) model.

\section{Lexical Decision and Lexical Access}

West and Stanovich (1982) suggested that conclusions from lexical decision experiments about the role of sentential context in word recognition are suspect, since the effects could be occurring at either a lexical access or a decision stage. More recently, Seidenberg, Waters, Sanders, and Langer (1984) compared priming effects in lexical decision and pronunciation tasks and concluded that semantic and associative priming effects are present in both tasks but that other contextual effects found with lexical decision tasks are due to postlexical processes. The results of our previous research and the present results lead us to agree with West and Stanovich and with Seidenberg et al. We (Balota \& Chumbley, 1984) found that the word-frequency effect is larger in the lexical decision task than it is in pronunciation and category verification tasks. From this we concluded that word frequency affected a decision stage instead of, or in addition to, speed of lexical access. The analyses of Experiments 2 and 3 presented in Table 6 support the same conclusion; word frequency has an effect in lexical decision beyond that attributable to the lexical access component shared by lexical decision, pronunciation, and associative responding. The results of the present research also demonstrate that performance in the lexical decision task is a least partly based on the availability of a word's meaning. These results indicate that it is not prudent to generalize the inferences made about the time course of lexical access and the variables affecting it from lexical decision experiments to tasks such as normal reading for which word/nonword decisions are not required.

\section{Alternatives to the Lexical Decision Task}

Under these conditions, it is important to consider the appropriateness of other tasks for studying variables affecting word recognition. West and Stanovich (1982) concluded that the pronunciation task is much better suited for studies of semantic context effects in word recognition. The results of Experiment 4 presented in Table 5 indicate that the pronunciation task is not sensitive to the meaning (as measured by I.DOM and LMEAN) of the isolated word (as might be expected if one assumes a logogen model of word production). This replicates our previous findings (Balota \& Chumbley, 1984). Thus, there is little evidence for effects of semantic variables on pronunciation latency. ${ }^{2}$ It would seem, then, that the pronunciation task may be apropriate for studying the effects of semantic context on lexical access.

The pronunciation task does, however, have a major limitation. We (Balota \& Chumbley, in press) found that the word-frequency effect observed in the pronunciation task has at least two components. One effect appears to be a word-frequency effect on lexical access, and the other seems to be associated with the production frequency of the word. The basic finding leading to these conclusions was that, although a word-frequency effect of approximately $60 \mathrm{msec}$ was found when subjects pronounced the word immediately upon presentation, there was still a word-frequency effect of approximately $45 \mathrm{msec}$ when the word had been in view for up to $400 \mathrm{msec}$ and the subject was simply delaying pronunciation of it until cued to respond. Moreover, another experiment using the same technique revealed significant word-frequency effects even though the word was available for close to $3 \mathrm{sec}$. Obviously, subjects have accessed the word's lexical representation in much less than $3 \mathrm{sec}$. Thus, special care must be taken to separate production-frequency effects from other frequency effects if the pronunciation task is to be used to study the role of word frequency in determining ease of lexical access.

The documentation of a word-frequency effect in word production by Balota and Chumbley (in press) provides an explanation for another puzzling result from the present set of experiments. The LFREQ effect found in the pronunciation task, Table 5, is, if anything, a little larger than that found for the lexical decision task of Experiment 3 , the upper portion of Table 4, even though exactly the same words and predictor variables were used. ${ }^{3}$ 
This is inconsistent with the results of Balota and Chumbley (1984) and other researchers (see Balota \& Chumbley, 1984, for a discusson of the usual result). In spite of the larger effect of LFREQ in pronunciation than in lexical decision, the reanalysis of Experiment 3 shown in Table 6 indicates that there was a LFREQ effect in lexical decision in addition to that shared with pronunciation. This "extra" LFREQ effect can be understood if one assumes there are at least two types of word-frequency effect: an effect on the decision stage in lexical decision; an effect on word production in pronunciation; and, quite possibly, a third effect of word frequency on lexical access. There is no reason to believe that familiarity/meaningfulness (as indexed by word frequency and meaning variables) should have an effect on pronunciation performance or that production frequency of words should have any effect on lexical decision performance. Thus, the "extra" frequency effect in lexical decision can be attributed to a familiarity/meaningfulness effect on lexical decision, and the large frequency effect in pronunciation undoubtedly includes a word-production frequency effect. $^{4}$

\section{CONCLUSIONS}

The experiments and analyses presented above clearly indicate that an isolated word's meaning affects some component of the lexical decision process other than lexical access. It is also possible that word meaning affects lexical access, but the results for the pronunciation task indicate this is probably not the case, at least not for isolated words. In any case, the meaning of a word is quickly available for use in reading.

Our results also indicate that word frequency affects the lexical decision task at some point other than lexical access. Since the pronunciation task also exhibited a large frequency effect, it could well be that word frequency also affects lexical access, although the role of production frequency must also be considered. It is clear, however, that the results of lexical decision experiments should not be used as evidence to support search theories of lexical access such as those of Becker (1980) or Forster (1978). A frequency-ordered search may be occurring, but the word-frequency effect in lexical decision may be primarily a function of the decision stage.

The differing results of Experiments 2 and 3 suggest that our subjects could use the length cues that were available in Experiment 2 (but not in Experiment 3). If this was the case, it points to the flexibility with which different types of information can be used in a very simple task that should require the use of only a highly automated word-recognition response. Thus, it appears that physical information is available earlier and/or is used more readily than semantic information even when the words are familiar and, for the most part, the meanings are wellknown. How this physical information is used in normal reading tasks is under study by a number of researchers (e.g., Pollatsek \& Rayner, 1982).
Finally, the present results replicate and extend those of Balota and Chumbley (1984) and provide additional support for the assumptions underlying our two-stage decision model of the lexical decision task. The success of the general form of this model in episodic memory tasks (e.g., Atkinson \& Juola, 1974; Mandler, 1980), semantic memory tasks (e.g., Smith, Shoben, \& Rips, 1974), and lexical decision tasks lends credence to its basic assumptions about the human propensity to use familiarity/meaningfulness information in making rapid judgments. If this assumption is correct, then it seems natural to assume that humans find this information easy to use and that its extraction is a very rapid and natural process. Again, the conclusion is encouraging for those who would pursue semantic context effects in word recognition tasks.

The outcome of this research effort can be viewed as both negative and positive. We believe that we have shown that the lexical decision task is a poor tool for studying semantic effects in isolated word recognition, a negative message. On the other hand, what we have learned about the nature of the information people use and the strategies they adopt in making lexical decisions seems to us to be very instructive in pointing to productive paths to follow in future research. For example, the sensitivity of the lexical decision task to the target word's meaning confirms the usefulness of the task in studying the effects of context on the speed with which the target word's meaning is available. We choose to accentuate the positive message-a word's meaning is quickly available for a multitude of purposes.

\section{REFERENCES}

AllPORT, D. A. (1977). On knowing the meaning of words we are unable to report: The effects of visual masking. In S. Dornic (Ed.), Attention and performance VI (pp. 505-533). Hillsdale, NJ: Erlbaum. ANDREWS, S. (1982). Phonological recoding: Is the regularity effect consistent? Memory \& Cognition, 10, 565-575.

Atkinson, R. C., \& Juola, J. F. (1974). Search and decision processes in recognition memory. In D. H. Krantz, R. C. Atkinson, R. D. Luce, \& P. Suppes (Eds.), Contemporary developments in mathematical psychology (Vol. 1, pp. 243-293). San Francisco: Freeman.

Balota D. A. (1983). Automatic semantic activation and episodic memory encoding. Journal of Verbal Learning and Verbal Behavior, 22, 88-104.

Balota, D. A., \& Chumbley, J. I. (1984). Are lexical decisions a good measure of lexical access? The role of word-frequency in the neglected decision stage. Journal of Experimental Psychology: Human Perception and Performance, 10, 340-357.

Balota, D. A., \& Chumbley, J. I. (in press). The locus of wordfrequency effects in the pronunciation task: Lexical access and/or production frequency? Journal of Memory and Language.

Battig, W. F., Montague, W. E. (1969). Category norms for verbal items in 56 categories: A replication and extension of the Connecticut category norms. Journal of Experimental Psychology Monographs, 80(3, Pt. 2).

BECKER, C. A. (1980). Semantic context effects in visual word recognition: An analysis of semantic strategies. Memory \& Cognition, 8 , 493-512.

Coltheart, M. (1978). Lexical access in simple reading tasks. In G. Underwood (Ed.), Strategies of information processing (pp. 151-216). London: Academic Press. 
DarLington, R. B. (1968). Multiple regression in psychological research. Psychological Bulletin, 69, 161-182.

DUCHEK, J. M., \& NeELY, J. H. (1984). Levels-of-processing and frequency effects in episodic and semantic memory. Manuscript in preparation.

Forster, K. I. (1978). Accessing the mental lexicon. In E. Walker (Ed.), Explorations in the biology of language (pp. 139-174). Montgomery, VT: Bradford Books.

FORSTER, K. I. (1981). Frequency blocking and lexical access: One mental lexicon or two? Journal of Verbal Learning and Verbal Behavior, 20, 190-203.

Forster, K. I. \& Chambers, S. M. (1973). Lexical access and naming time. Journal of Verbal Learning and Verbal Behavior, 12, 627-635.

Glanzer, M., \& Ehrenreich, S. L. (1979). Structure and search of the internal lexicon. Journal of Verbal Learning and Verbal Behavior, 18, 381-398.

GLusHKo, R. J. (1981). Principles for pronouncing print: The psychology of phonography. In A. M. Lesgold \& C. A. Perfetti (Eds.), Interactive processes in reading (pp. 61-84). Hillsdale, NJ: Erlbaum

GoRDON, B. (1983). Lexical access and lexical decision: Mechanisms of frequency sensitivity. Journal of Verbal Learning and Verbal Behavior, 22, 24-44.

JAMES, C. T. (1975). The role of semantic information in lexical decisions. Journal of Experimental Psychology: Human Perception and Performance, 1, 130-136.

JASTRZEMBSKI, J. E. (1981). Multiple meanings, number of related meanings, frequency of occurrence, and the lexicon. Cognitive Psychology, 13, 278-305.

KUĆERA, H., \& FRANCIS, W. (1967). A computational analysis of presentday American English. Providence, RI: Brown University Press.

MANDLeR, G. (1980). Recognizing: The judgment of previous occurrence. Psychological Review, 87, 252-271.

MARCEL, A. J. (1983). Conscious and unconscious perception: An approach to the relations between phenomenal experience and perceptual processes. Cognitive Psychology, 15, 238-300.

MarCel, A. J., \& PatTerson, K. E. (1978). Word recognition and production: Reciprocity in clinical and normal studies. In J. Requin (Ed.), Attention and performance VII (pp. 209-226). Hillsdale, NJ: Erlbaum.

McKoon, G., \& Ratcliff, R. (1979). Priming in episodic and semantic memory. Journal of Verbal Learning and Verbal Behavior, 18, 463-480.

Morton, J. (1970). A functional model for memory. In D. A. Norman (Ed.), Models of human memory (pp. 203-254). New York: Academic Press.

MoRTON, J. (1979a). Facilitation in word recognition: Experiments causing change in the logogen model. In P. A. Kolers, M. E. Wrolstad, \& H. Bouma (Eds.), Processing of visible language (Vol. 1, pp. 259268). New York: Plenum.

Morton, J. (1979b). Word recognition. In J. Morton \& J. C. Marshall (Eds.), Psycholinguistics 2: Structures and processes (pp. 106156). Cambridge, MA: MIT Press.

MoRTon, J. (1982). Disintegrating the lexicon: An information processing approach. In J. Mehler, S. Franck, E. C. T. Walker, \& M. Garrett (Eds.), Perspectives on mental representation (pp. 89-109). Hillsdale, NJ: Erlbaum.

Pollatsek, A., \& RAyner, K. (1982). Eye movement control in reading: The role of word boundaries. Journal of Experimental Psychology: Human Perception and Performance, 8, 817-833.

Scarborough, D. L., Cortese, C., \& Scarborough, H. S. (1977) Frequency and repetition effects in lexical memory. Journal of Ex perimenal Psychology: Human Perception and Performance, 3, 1-17.

Scarborough, D. L., Gerard, L., \& Cortese, C. (1979). Accessing lexical memory: The transfer of word repetition effects across task and modality. Memory \& Cognition, 7, 3-12.

SchuberTh, R. E., \& Eimas, P. D. (1977). Effects of context on the classification of words and nonwords. Journal of Experimental Psychology: Human Perception and Performance, 3, 27-36.
Seidenburg, M. S., Waters, G. S., Sanders, M., \& Langer, P. (1984). Pre- and postlexical loci of contextual effects on word recognition. Memory \& Cognition, 12, 315-328.

Smith, E. E., Shoben, E. J., \& RuPs, L. J. (1974). Structure and process in semantic memory: A featural model for semantic decisions. Psychological Review, 81, 214-241.

West, R. F., \& Stanovich, K. E. (1982). Source of inhibition in experiments on the effect of sentence context on word recognition. Journal of Experimental Psychology: Learning, Memory, and Cognition, 8, 385-399.

WhaLEY, C. P. (1978). Word-nonword classification time. Journal of Verbal Learning and Verbal Behavior, 17, 143-154.

\section{NOTES}

1. Regression analyses reported here and below that included I.DOM, LFREQ, LENG, LMEAN, and \#ARSP as predictor variables were repeated omitting \#ARSP as a predictor variable. The results were essentially the same as might be expected given the tolerance value for \#ARSP. Thus, the inclusion of the somewhat unusual \#ARSP variable as a predictor variable is not distorting the results with respect to the other variables.

2. We do not think we have any strong evidence that the meaning of an isolated word has an important impact on performance in the pronunciation task. One of our analyses, which is not reported in full here, could be construed to indicate there are meaning effects in pronunciation, but there is, to us, a more plausible explanation. A multiple regression analysis like that in the lower portion of Table 6, but with the roles of lexical decision RT and pronunciation RT reversed, indicated that associative $\mathrm{RT}$ was significantly related to pronunciation $\mathrm{RT}$ beyond its common relation through lexical access. We believe this probably was due to a tendency of the subjects to subvocally pronounce the stimulus word as they were thinking of an associate to produce aloud. This would not tend to happen anywhere nearly as often in the lexical decision task (its RTs were less than half the size of the association RTs), and, to the extent it did, the variance attributable to this effect in all three tasks would be part of the shared variance in Table 6. Of course, at this point this is only a post hoc explanation, and the role of meaning in the pronunciation task requires further investigation.

3. Some readers may be concerned about the fact that the $\mathrm{r}$ for LFREQ and lexical decision RT in Experiment 3 was - .558, whereas the $r$ for LFREQ and pronunciation RT was -.517 . The rs thus have a relationship opposite to that of the regression coefficients. This fact is readily explained. The unadjusted frequency effect in lexical decision is being inflated by the indirect effect of I.DOM, with which it is correlated ( $r$ $=.402$ ). When this indirect effect is partialed out by the regression analysis, the direct effect of LFREQ is actually smaller in lexical decision than it is in pronunciation. This illustrates one problem with some applications of multiple regression techniques. If one found that the correlation between I.DOM and lexical decision RT was perfect $(-1.0)$ and was sure that it was the relevant variable, LFREQ would have a correlation with lexical decision RT of -.402 because of the indirect effect of I.DOM. In addition, the direct effect of I.DOM reflected in the regression coefficient would be much smaller than -1.0 . Fortunately, this problem does not arise in the comparison made here. Task is orthogonal to the predictor variables, and the effects of colinearity are the same for both tasks. Any change in an $r$ or a regression coefficient must be due to a change in the relationship of the variable to task performance.

4. The analysis described in Footnote 2 resulted in a nearly significant $(p=.056)$ LFREQ regression coefficient of -8.151 . Multiplying this by 4 gives a 32-msec production-frequency effect, close to the size of the production-frequency effect found by Balota and Chumbley (in press). For the reasons alluded to in Footnote 3, that is, the set of predictor variables has changed, this "production-frequency regression coefficient" cannot be directly compared with the "decision-frequency regression coefficient" of Table 6 with any expectation that the comparison will yield reliable results. 
APPENDIX

Words, Reaction Times (RTs), and Combined Error/Outlier Percentages (\%E/O)

\begin{tabular}{|c|c|c|c|c|c|c|c|c|c|}
\hline & \multirow[b]{2}{*}{ Word } & \multicolumn{2}{|c|}{$\begin{array}{c}\text { Experiment } 1 \\
\text { Associative } \\
\text { Responses } \\
\end{array}$} & \multicolumn{2}{|c|}{$\begin{array}{c}\text { Experiment } 2 \\
\text { Lexical } \\
\text { Decisions } \\
\end{array}$} & \multicolumn{2}{|c|}{$\begin{array}{c}\text { Experiment } 3 \\
\text { Lexical } \\
\text { Decisions } \\
\end{array}$} & \multicolumn{2}{|c|}{$\begin{array}{c}\text { Experiment } 4 \\
\text { Pronunciation } \\
\text { Responses } \\
\end{array}$} \\
\hline & & RT & $\% \mathrm{E} / \mathrm{O}$ & RT & $\% \mathrm{E} / \mathrm{O}$ & RT & $\% \mathrm{E} / \mathrm{O}$ & $\mathrm{RT}$ & $\% \mathrm{E} / \mathrm{O}$ \\
\hline 1 & DIAMOND & 1235 & 0.0 & 546 & 0.0 & 549 & 0.0 & 543 & 0.0 \\
\hline 2 & JADE & 1339 & 4.2 & 603 & 4.2 & 611 & 8.3 & 492 & 0.0 \\
\hline 3 & RUBY & 1448 & 0.0 & 584 & 0.0 & 562 & 4.2 & 569 & 8.3 \\
\hline 4 & GEM & 1394 & 0.0 & 658 & 16.7 & 629 & 4.2 & 564 & 4.2 \\
\hline 5 & MILE & 1562 & 0.0 & 650 & 33.3 & 635 & 8.3 & 517 & 0.0 \\
\hline 6 & ACRE & 1521 & 0.0 & 601 & 16.7 & 598 & 4.2 & 637 & 0.0 \\
\hline 7 & METER & 1566 & 0.0 & 665 & 12.5 & 643 & 33.3 & 570 & 0.0 \\
\hline 8 & FATHOM & 1777 & 16.7 & 721 & 50.0 & 689 & 29.2 & 771 & 12.5 \\
\hline 9 & IRON & 1402 & 0.0 & 522 & 0.0 & 545 & 4.2 & 501 & 4.2 \\
\hline 10 & BRONZE & 1320 & 0.0 & 520 & 0.0 & 573 & 0.0 & 540 & 0.0 \\
\hline 11 & COPPER & 1376 & 0.0 & 555 & 0.0 & 553 & 4.2 & 528 & 0.0 \\
\hline 12 & PLATINUM & 1653 & 12.5 & 631 & 25.0 & 709 & 12.5 & 666 & 8.3 \\
\hline 13 & BOOK & 1209 & 4.2 & 495 & 0.0 & 489 & 0.0 & 481 & 4.2 \\
\hline 14 & POETRY & 1594 & 4.2 & 518 & 0.0 & 592 & 4.2 & 573 & 0.0 \\
\hline 15 & MAGAZINE & 1481 & 0.0 & 555 & 4.2 & 557 & 0.0 & 520 & 0.0 \\
\hline 16 & ESSAY & 1331 & 4.2 & 546 & 4.2 & 572 & 0.0 & 557 & 0.0 \\
\hline 17 & HORSE & 1305 & 0.0 & 566 & 0.0 & 499 & 0.0 & 493 & 0.0 \\
\hline 18 & RABBIT & 1625 & 8.3 & 514 & 0.0 & 517 & 0.0 & 478 & 0.0 \\
\hline 19 & TIGER & 1567 & 0.0 & 494 & 4.2 & 501 & 0.0 & 497 & 4.2 \\
\hline 20 & LEOPARD & 1299 & 4.2 & 554 & 0.0 & 587 & 0.0 & 543 & 4.2 \\
\hline 21 & WOOL & 1458 & 0.0 & 508 & 0.0 & 572 & 0.0 & 539 & 0.0 \\
\hline 22 & VELVET & 1331 & 0.0 & 530 & 0.0 & 531 & 0.0 & 546 & 4.2 \\
\hline 23 & RAYON & 1636 & 20.8 & 663 & 54.2 & 660 & 33.3 & 589 & 0.0 \\
\hline 24 & ORLON & 1724 & 20.8 & 645 & 79.2 & 652 & 70.8 & 704 & 8.3 \\
\hline 25 & BLACK & 994 & 4.2 & 482 & 0.0 & 513 & 0.0 & 478 & 0.0 \\
\hline 26 & GRAY & 1321 & 0.0 & 567 & 0.0 & 536 & 4.2 & 553 & 0.0 \\
\hline 27 & YELLOW & 1360 & 0.0 & 487 & 0.0 & 502 & 4.2 & 459 & 0.0 \\
\hline 28 & INDIGO & 1631 & 8.3 & 735 & 29.2 & 698 & 37.5 & 705 & 12.5 \\
\hline 29 & PAN & 1617 & 4.2 & 594 & 0.0 & 577 & 0.0 & 543 & 0.0 \\
\hline 30 & OVEN & 1132 & 0.0 & 550 & 0.0 & 521 & 0.0 & 482 & 0.0 \\
\hline 31 & SPOON & 1210 & 0.0 & 513 & 0.0 & 530 & 0.0 & 526 & 0.0 \\
\hline 32 & LADLE & 1447 & 0.0 & 661 & 33.3 & 660 & 20.8 & 540 & 4.2 \\
\hline 33 & VERB & 1259 & 0.0 & 616 & 25.0 & 598 & 29.2 & 566 & 4.2 \\
\hline 34 & WORDS & 1742 & 12.5 & 558 & 0.0 & 551 & 0.0 & 509 & 0.0 \\
\hline 35 & PRONOUN & 1605 & 8.3 & 630 & 45.8 & 659 & 41.7 & 720 & 33.3 \\
\hline 36 & GERUND & 2038 & 29.2 & 635 & 70.8 & 668 & 75.0 & 660 & 45.8 \\
\hline 37 & LAMP & 1141 & 4.2 & 531 & 0.0 & 554 & 0.0 & 459 & 0.0 \\
\hline 38 & BENCH & 1312 & 0.0 & 559 & 4.2 & 544 & 0.0 & 477 & 4.2 \\
\hline 39 & SOFA & 1099 & 4.2 & 518 & 0.0 & 552 & 0.0 & 495 & 4.2 \\
\hline 40 & ROCKER & 1537 & 0.0 & 577 & 0.0 & 608 & 12.5 & 550 & 0.0 \\
\hline 41 & HEAD & 1571 & 0.0 & 561 & 0.0 & 514 & 0.0 & 498 & 8.3 \\
\hline 42 & BRAIN & 1493 & 0.0 & 520 & 0.0 & 538 & 0.0 & 505 & 0.0 \\
\hline 43 & EYE & 1339 & 0.0 & 477 & 0.0 & 501 & 0.0 & 470 & 0.0 \\
\hline 44 & LIVER & 1538 & 0.0 & 507 & 4.2 & 550 & 4.2 & 491 & 4.2 \\
\hline 45 & CHERRY & 1401 & 0.0 & 533 & 0.0 & 517 & 0.0 & 501 & 4.2 \\
\hline 46 & COCONUT & 1586 & 4.2 & 528 & 0.0 & 554 & 0.0 & 557 & 4.2 \\
\hline 47 & PLUM & 1376 & 0.0 & 578 & 4.2 & 544 & 0.0 & 533 & 0.0 \\
\hline 48 & CANTELOPE* & 1538 & 0.0 & 566 & 0.0 & 651 & 8.3 & 620 & 0.0 \\
\hline 49 & PRESIDENT & 1672 & 8.3 & 575 & 0.0 & 548 & 0.0 & 568 & 0.0 \\
\hline 50 & JUDGE & 1556 & 4.2 & 479 & 0.0 & 555 & 4.2 & 501 & 0.0 \\
\hline 51 & SENATOR & 1523 & 12.5 & 506 & 4.2 & 563 & 0.0 & 554 & 4.2 \\
\hline 52 & SHERIFF & 1456 & 0.0 & 553 & 4.2 & 618 & 8.3 & 531 & 0.0 \\
\hline 53 & BEER & 1228 & 0.0 & 510 & 0.0 & 516 & 0.0 & 504 & 4.2 \\
\hline 54 & CHAMPAGNE & 1625 & 4.2 & 555 & 0.0 & 597 & 0.0 & 629 & 8.3 \\
\hline 55 & GIN & 1286 & 4.2 & 609 & 8.3 & 601 & 12.5 & 538 & 0.0 \\
\hline 56 & VERMOUTH & 1619 & 12.5 & 647 & 12.5 & 723 & 16.7 & 652 & 12.5 \\
\hline 57 & PRIEST & 1454 & 0.0 & 547 & 4.2 & 631 & 8.3 & 601 & 4.2 \\
\hline 58 & PREACHER & 1714 & 8.3 & 644 & 4.2 & 662 & 8.3 & 631 & 4.2 \\
\hline 59 & RABBI & 1763 & 0.0 & 694 & 12.5 & 660 & 29.2 & 603 & 0.0 \\
\hline 60 & MONK & 1716 & 0.0 & 629 & 20.8 & 671 & 25.0 & 572 & 0.0 \\
\hline 61 & SALT & 1241 & 0.0 & 504 & 8.3 & 499 & 0.0 & 479 & 4.2 \\
\hline 62 & LEMON & 1219 & 0.0 & 549 & 8.3 & 543 & 4.2 & 468 & 0.0 \\
\hline
\end{tabular}




\begin{tabular}{|c|c|c|c|c|c|c|c|c|c|}
\hline 63 & PEPPER & 1058 & 0.0 & 610 & 0.0 & 557 & 8.3 & 524 & 4.2 \\
\hline 64 & HERBS & 1707 & 0.0 & 596 & 8.3 & 601 & 8.3 & 565 & 4.2 \\
\hline 65 & OIL & 1381 & 8.3 & 489 & 0.0 & 481 & 0.0 & 464 & 0.0 \\
\hline 66 & STEAM & 1423 & 0.0 & 581 & 0.0 & 547 & 0.0 & 544 & 4.2 \\
\hline 67 & COAL & 1406 & 0.0 & 508 & 8.3 & 590 & 0.0 & 501 & 4.2 \\
\hline 68 & BUTANE & 1366 & 4.2 & 638 & 45.8 & 657 & 41.7 & 714 & 8.3 \\
\hline 69 & TEACHER & 1580 & 0.0 & 465 & 0.0 & 497 & 0.0 & 492 & 0.0 \\
\hline 70 & BANKER & 1500 & 4.2 & 524 & 0.0 & 553 & 0.0 & 540 & 0.0 \\
\hline 71 & LAWYER & 1774 & 4.2 & 554 & 0.0 & 562 & 0.0 & 484 & 0.0 \\
\hline 72 & MERCHANT & 1565 & 0.0 & 570 & 0.0 & 625 & 0.0 & 570 & 0.0 \\
\hline 73 & RIVER & 1270 & 0.0 & 530 & 4.2 & 529 & 4.2 & 473 & 4.2 \\
\hline 74 & CREEK & 1386 & 8.3 & 584 & 8.3 & 607 & 8.3 & 542 & 8.3 \\
\hline 75 & VALLEY & 1701 & 0.0 & 566 & 8.3 & 594 & 0.0 & 512 & 0.0 \\
\hline 76 & GORGE & 1834 & 20.8 & 671 & 45.8 & 685 & 37.5 & 606 & 29.2 \\
\hline 77 & BASEBALL & 1331 & 4.2 & 526 & 0.0 & 546 & 0.0 & 539 & 0.0 \\
\hline 78 & BOXING & 1337 & 0.0 & 480 & 0.0 & 567 & 0.0 & 507 & 0.0 \\
\hline 79 & TENNIS & 1336 & 0.0 & 501 & 0.0 & 530 & 0.0 & 512 & 0.0 \\
\hline 80 & HUNTING & 1349 & 4.2 & 532 & 0.0 & 585 & 8.3 & 528 & 0.0 \\
\hline 81 & RAIN & 1384 & 0.0 & 500 & 0.0 & 512 & 4.2 & 494 & 0.0 \\
\hline 82 & FOG & 1588 & 0.0 & 565 & 4.2 & 510 & 4.2 & 492 & 0.0 \\
\hline 83 & TORNADO & 1411 & 0.0 & 621 & 0.0 & 641 & 16.7 & 628 & 4.2 \\
\hline 84 & MONSOON & 1696 & 16.7 & 718 & 29.2 & 631 & 54.2 & 782 & 8.3 \\
\hline 85 & SHIRT & 1458 & 0.0 & 487 & 4.2 & 498 & 0.0 & 474 & 0.0 \\
\hline 86 & SUIT & 1432 & 0.0 & 536 & 4.2 & 550 & 4.2 & 498 & 0.0 \\
\hline 87 & SOCKS & 1315 & 4.2 & 515 & 0.0 & 518 & 0.0 & 507 & 0.0 \\
\hline 88 & SCARF & 1450 & 4.2 & 572 & 0.0 & 613 & 0.0 & 524 & 0.0 \\
\hline 89 & DOOR & 1163 & 0.0 & 477 & 0.0 & 498 & 0.0 & 495 & 0.0 \\
\hline 90 & KITCHEN & 1293 & 0.0 & 484 & 0.0 & 520 & 0.0 & 472 & 0.0 \\
\hline 91 & ROOF & 1310 & 4.2 & 521 & 0.0 & 535 & 4.2 & 459 & 0.0 \\
\hline 92 & ATTIC & 1471 & 0.0 & 563 & 0.0 & 575 & 4.2 & 496 & 0.0 \\
\hline 93 & PIANO & 1218 & 0.0 & 529 & 4.2 & 545 & 4.2 & 537 & 0.0 \\
\hline 94 & BUGLE & 1635 & 0.0 & 651 & 4.2 & 624 & 4.2 & 632 & 12.5 \\
\hline 95 & TRUMPET & 1377 & 0.0 & 523 & 4.2 & 578 & 0.0 & 519 & 4.2 \\
\hline 96 & BASSOON & 2134 & 12.5 & 601 & 33.3 & 692 & 33.3 & 720 & 25.0 \\
\hline 97 & CORN & 1352 & 4.2 & 508 & 0.0 & 510 & 8.3 & 508 & 4.2 \\
\hline 98 & ONIONS & 1597 & 0.0 & 564 & 0.0 & 544 & 0.0 & 524 & 0.0 \\
\hline 99 & CARROT & 1406 & 4.2 & 519 & 0.0 & 531 & 0.0 & 499 & 0.0 \\
\hline 100 & CABBAGE & 1504 & 0.0 & 587 & 4.2 & 556 & 0.0 & 579 & 4.2 \\
\hline 101 & SHOE & 1357 & 0.0 & 560 & 0.0 & 511 & 4.2 & 455 & 4.2 \\
\hline 102 & HEELS & 1247 & 0.0 & 642 & 8.3 & 676 & 4.2 & 572 & 8.3 \\
\hline 103 & BOOTS & 1429 & 0.0 & 524 & 4.2 & 533 & 4.2 & 490 & 4.2 \\
\hline 104 & SKATES & 1275 & 0.0 & 522 & 0.0 & 586 & 0.0 & 569 & 0.0 \\
\hline 105 & SALMON & 1459 & 8.3 & 616 & 4.2 & 599 & 4.2 & 675 & 0.0 \\
\hline 106 & LOBSTER & 1632 & 0.0 & 505 & 0.0 & 519 & 0.0 & 489 & 0.0 \\
\hline 107 & TUNA & 1070 & 0.0 & 534 & 0.0 & 514 & 0.0 & 497 & 0.0 \\
\hline 108 & GUPPY & 1360 & 0.0 & 740 & 25.0 & 700 & 29.2 & 591 & 0.0 \\
\hline 109 & CAPTAIN & 1467 & 0.0 & 544 & 4.2 & 580 & 0.0 & 565 & 0.0 \\
\hline 110 & COMMANDER & 1524 & 0.0 & 569 & 0.0 & 635 & 8.3 & 638 & 4.2 \\
\hline 111 & SERGEANT & 1670 & 8.3 & 576 & 0.0 & 601 & 8.3 & 640 & 0.0 \\
\hline 112 & ENSIGN & 1868 & 29.2 & 625 & 70.8 & 655 & 54.2 & 714 & 12.5 \\
\hline 113 & CHAPEL & 1526 & 0.0 & 578 & 0.0 & 604 & 12.5 & 560 & 0.0 \\
\hline 114 & SHRINE & 1679 & 4.2 & 675 & 20.8 & 661 & 16.7 & 553 & 0.0 \\
\hline 115 & SYNAGOGUE & 1869 & 4.2 & 633 & 16.7 & 649 & 29.2 & 704 & 16.7 \\
\hline 116 & MONASTERY & 1821 & 4.2 & 677 & 8.3 & 714 & 8.3 & 694 & 4.2 \\
\hline 117 & BOMB & 1593 & 0.0 & 572 & 0.0 & 540 & 4.2 & 520 & 0.0 \\
\hline 118 & REVOLVER & 1255 & 4.2 & 630 & 0.0 & 653 & 4.2 & 591 & 0.0 \\
\hline 119 & SWORD & 1310 & 4.2 & 595 & 8.3 & 573 & 8.3 & 573 & 0.0 \\
\hline 120 & BAZOOKA & 1319 & 0.0 & 597 & 12.5 & 678 & 4.2 & 631 & 0.0 \\
\hline 121 & HOUSE & 1409 & 0.0 & 477 & 0.0 & 499 & 0.0 & 476 & 0.0 \\
\hline 122 & TEPEE & 1358 & 0.0 & 665 & 58.3 & 655 & 70.8 & 601 & 8.3 \\
\hline 123 & APARTMENT & 1296 & 4.2 & 523 & 0.0 & 568 & 0.0 & 607 & 0.0 \\
\hline 124 & PALACE & 1571 & 8.3 & 544 & 4.2 & 558 & 0.0 & 584 & 4.2 \\
\hline 125 & ROBBERY & 1522 & 4.2 & 545 & 4.2 & 581 & 4.2 & 539 & 8.3 \\
\hline 126 & FORGERY & 1844 & 4.2 & 627 & 12.5 & 652 & 4.2 & 683 & 0.0 \\
\hline 127 & ASSAULT & 1524 & 4.2 & 572 & 0.0 & 585 & 0.0 & 544 & 0.0 \\
\hline 128 & SUICIDE & 1320 & 4.2 & 556 & 0.0 & 573 & 0.0 & 548 & 0.0 \\
\hline 129 & MONTH & 1162 & 0.0 & 516 & 8.3 & 566 & 0.0 & 496 & 4.2 \\
\hline 130 & ETERNITY & 1461 & 4.2 & 620 & 12.5 & 663 & 25.0 & 696 & 4.2 \\
\hline 131 & DECADE & 1439 & 0.0 & 621 & 0.0 & 599 & 4.2 & 571 & 4.2 \\
\hline
\end{tabular}




\begin{tabular}{|c|c|c|c|c|c|c|c|c|c|}
\hline 132 & MILLENIUM* & 2007 & 29.2 & 679 & 58.3 & 682 & 62.5 & 630 & 54.2 \\
\hline 133 & EAGLE & 1158 & 0.0 & 493 & 0.0 & 493 & 0.0 & 468 & 0.0 \\
\hline 134 & CHICKEN & 1441 & 4.2 & 480 & 4.2 & 538 & 0.0 & 481 & 0.0 \\
\hline 135 & SPARROW & 1192 & 0.0 & 612 & 4.2 & 619 & 4.2 & 614 & 0.0 \\
\hline 136 & VULTURE & 1469 & 4.2 & 594 & 12.5 & 653 & 25.0 & 582 & 0.0 \\
\hline 137 & FATHER & 1209 & 0.0 & 517 & 0.0 & 506 & 0.0 & 528 & 0.0 \\
\hline 138 & SON & 1209 & 0.0 & 538 & 12.5 & 526 & 4.2 & 477 & 0.0 \\
\hline 139 & COUSIN & 1430 & 0.0 & 540 & 0.0 & 541 & 0.0 & 583 & 0.0 \\
\hline 140 & WIFE & 1274 & 0.0 & 530 & 12.5 & 589 & 0.0 & 511 & 0.0 \\
\hline 141 & COFFEE & 1102 & 0.0 & 491 & 0.0 & 517 & 0.0 & 495 & 0.0 \\
\hline 142 & JUICE & 1356 & 0.0 & 521 & 0.0 & 536 & 0.0 & 516 & 12.5 \\
\hline 143 & TEA & 1072 & 0.0 & 502 & 0.0 & 491 & 0.0 & 476 & 0.0 \\
\hline 144 & SODA & 1468 & 0.0 & 529 & 0.0 & 515 & 4.2 & 452 & 0.0 \\
\hline
\end{tabular}

*We misspelled these words, but so did Battig and Montague (1969).

(Manuscript received November 4, 1983;

revision accepted for publication July 16,1984 .) 